\title{
GESTÃO DEMOCRÁTICA E CRISE ESTRUTURAL DO CAPITAL: ALGUNS APONTAMENTOS
}

\author{
GESTIÓN DEMOCRÁTICA Y LA CRISIS ESTRUCTURAL DEL CAPITAL: ALGUNAS \\ NOTAS
}

\section{DEMOCRATIC MANAGEMENT AND STRUCTURAL CRISIS OF CAPITAL: SOME POINTS}

\author{
Adriana Mota de Oliveira SIDOU ${ }^{1}$ \\ Agercicleiton Coelho GUERRA ${ }^{2}$ \\ José Deribaldo Gomes dos SANTOS ${ }^{3}$
}

RESUMO: O artigo objetiva debater o princípio da gestão democrática em relação à crise estrutural do capital, que, segundo Mészáros, tem início na década de 1970. Opta-se por uma pesquisa teórica, documental e bibliográfica. Sob a orientação desses pressupostos, observa-se que os desdobramentos dessa crise assolam todos os complexos sociais. Os sistemas educacionais, sobretudo os localizados nos países que orbitam na periferia do grande capital, como o Brasil, passam a ser monitorados pelos organismos internacionais. Essas agências têm como finalidade desresponsabilizar o Estado de suas atribuições de execução e financiamento educacional. Para isso, montam requintados processos de monitoramento. A gestão democrática para a educação imersa nesse cenário apresenta-se como um princípio que deve corroborar com as políticas de diminuição das funções estatais.

PALAVRAS-CHAVE: Educação. Gestão. Crise estrutural do capital.

RESUMEN: El artículo tiene como objetivo el debate del principio de gestión democrática en relación con la crisis estructural del capital, que, según Mészáros, comienza en la década de 1970. La opción es por una investigación teórica, documental y bibliográfica. Bajo la guía de estos supuestos, se observa que las consecuencias de esta crisis afectan a todos los complejos sociales. Los sistemas educativos, especialmente aquellos ubicados en países que orbitan em la periferia del gran capital, como Brasil, ahora son monitoreados por organizaciones internacionales. Estas agencias tienen el propósito de hacer que el Estado no sea responsable de sus atribuciones de ejecución educativa y financieras. Para esto, establecieron especiales procesos de monitoreo. La gestión democrática para la educación inmersa en este escenario se presenta como un principio que debe corroborar con las políticas para reducir las funciones estatales.

${ }^{1}$ Universidade Estadual do Ceará (UECE), Fortaleza - CE - Brasil. Doutoranda no Programa de Pós-graduação em Educação. ORCID: https://orcid.org/0000-0003-1830-7740. E-mail: amsidou@ gmail.com

${ }^{2}$ Universidade Estadual do Ceará (UECE), Fortaleza - CE - Brasil. Doutorando no Programa de Pós-graduação em Educação. ORCID: https://orcid.org/0000-0002-8377-8971. E-mail: age.guerra@aluno.uece.br

${ }^{3}$ Universidade de Educação, Ciências e Letras do Sertão Central (FECLESC), Quixadá - CE - Brasil. Professor Adjunto da Faculdade de Educação, Ciências e Letras do Sertão Central (FECLESC-UECE), atuando no Programa de Pós-Graduação em Educação (PPGE/UECE) e no Mestrado Acadêmico Intercampi em Educação e Ensino (MAIE/UECE). ORCID: https://orcid.org/0000-0001-7915-0885. E-mail: deribaldo.santos@uece.br 
PALABRAS CLAVE: Educación. Gestión. Crisis estructural del capital.

ABSTRACT: The article, as a theoretical, documentary and bibliographic research, aims to debate the principle of democratic management in relation to the structural crisis of capital, which, according to Mészáros, begins in the 1970s. Under the guidance of these assumptions, it is observed that the consequences of this crisis affect all social complexes. Educational systems, especially those located in countries that orbit the periphery of big capital, such as Brazil, are now monitored by international organizations. These agencies have the purpose of making the State not responsible for its educational execution and financing attributions. For this, they set up exquisite monitoring processes. Democratic management for education immersed in this scenario presents itself as a principle that must corroborate with the policies to reduce state functions.

KEYWORDS: Education. Management. Structural crisis of capital.

\section{Introdução}

A exposição tematiza a gestão democrática e sua relação com a crise estrutural do capital. A pesquisa está situada sob as coordenadas da ontologia materialista, inaugurada por Marx e recuperada por Lukács, que concebe o ser social como um complexo de complexos, que tem no trabalho o seu momento fundante.

O trabalho para Marx é o momento em que homens e mulheres, por meio de atos teleológicos, transformam a natureza ao mesmo tempo em que modificam a própria natureza humana. O trabalho constitui-se no momento fundante do ser social e é por intermédio dele que a humanidade se afasta das barreiras naturais. $\mathrm{O}$ trabalho como atividade mediadora entre o sujeito humano e a natureza, ao criar o ser social, torna-se modelo para outros complexos sociais. As necessidades postas pelo trabalho dão origem, paulatinamente, a novas necessidades sociais. O surgimento dos novos complexos sociais, a exemplo de educação, política, direito, dentre outros, retroagem sobre o trabalho enriquecendo-o. Entre esses novos complexos sociais e o trabalho cria-se determinado grau de dependência ontológica e autonomia relativa, em que a predominância recai sobre o momento fundante.

O método, por sua vez, representa uma expressão do movimento do real, que parte das inúmeras determinações vinculadas ao fenômeno estudado, articulado com o processo de reprodução social em sua totalidade.

Neste sentido, a função social da educação, dentro do processo de reprodução social, é o de permitir aos indivíduos a apropriação dos conhecimentos, habilidades, valores e 
comportamentos que lhe permitam participar do gênero humano, ou seja, da apropriação do patrimônio humano historicamente acumulado.

A educação enquanto um complexo social, não poderia, portanto, deixar de ser permeada pelas contradições ora postas pelo modo de produção vigente. No caso específico da gestão democrática, temos um princípio constitucional sob o qual deverá ser organizada a educação no Brasil; princípio este, que a presente pesquisa pretende analisar, tomando como base uma investigação de caráter teórico e bibliográfico, destacando, sobretudo, o papel que desempenha no atual contexto do capitalismo contemporâneo, e para, além disso, entender quais os limites e possibilidades da gestão democrática dentro da escola pública.

Com o objetivo definido, dividiu-se o artigo em duas partes articuladas entre si: na primeira realizou-se uma breve discussão sobre a crise estrutural do capital e na segunda contextualizou-se o surgimento da gestão democrática e sua trajetória para o campo da Educação, procurando demonstrar que o princípio da gestão democrática ressurgiu em um momento denominado por Mészáros (2011a) como crise estrutural do capital, e que se vinculou às políticas de reestruturação do país, fortemente articuladas com as demandas internacionais que orientam menor participação financeira do Estado, a partir do incentivo à participação da comunidade, mantendo-se centralizadas as políticas e o poder de decisão.

\section{Crise estrutural do capital: um breve entendimento}

Não há dúvida de que o mundo atual vive uma crise sem precedente em sua história. Existem várias hipóteses sobre a origem e o desdobramento de tal crise. A presente exposição, para compreender o momento atual, prioriza as pesquisas de Mészáros (2011a), cuja análise entende que hoje o mundo vive uma crise estrutural do capital. Para esse autor, a crise contemporânea apresenta uma perigosa distinção daquelas verificadas no passado. Esta não é como as anteriores, cíclica; trata-se de uma crise estrutural.

De acordo com Mészáros (2011b), a crise estrutural possui quatro aspectos principais: (1) o seu caráter é universal, e por isto não se restringe às esferas financeira e comercial, ou a um ramo particular da produção; (2) seu alcance é global, na medida em que não se limita a um conjunto particular de países; (3) sua escala de tempo é permanente, ou seja, a crise é intermitente e seus reflexos estão sempre presentes e; (4) esta crise se desdobra de modo rastejante, visto o vasto arsenal que se põe em movimento para diminuir os seus efeitos.

A crise estrutural do capital se difere da crise de essência cíclica, na medida em que, nesta nova fase, não há intervalos entre momentos de expansão e recessão, mas constitui-se de 
momentos marcados por "eclosão de precipitações cada vez mais frequentes e contínuas" (MÉSZÁROS, 2011a, p. 12). Outra divergência entre a crise cíclica e a estrutural, é que esta classe de crise "[...] afeta a totalidade de um complexo social em todas as suas relações com suas partes constituintes ou subcomplexos, como também a outros complexos aos quais é articulada” (MÉSZÁROS, 2011b, p. 796), enquanto em momentos de crises cíclicas apenas partes de um complexo são afetados.

O filósofo húngaro, para demonstrar as distinções entre o que se vive hoje e as convulsões econômicas do passado, lembra que na época de Marx a confiança da classe dominante era tanta, que ela usava as páginas dos jornais para conversar consigo mesma. $\mathrm{Na}$ atualidade, esta mesma classe precisa de um “[...] órgão de propaganda de circulação em massa, com o objetivo de mistificação geral” (MÉSZÁROS, 2011a, p. 19). Os problemas da humanidade são contados a partir do ponto de vista de quem precisa mascarar as reais causas dos problemas.

\begin{abstract}
Alguém pode pensar numa maior acusação para um sistema de produção econômica e reprodução social pretensamente insuperável do que esta: no auge de seu poder produtivo, está produzindo uma crise alimentar global e o sofrimento decorrente dos incontáveis milhões de pessoas por todo o mundo? Essa é a natureza do sistema que se espera salvar agora a todo o custo, incluindo a atual "divisão" do seu custo astronômico (MÉSZÁROS, 2011a, p. 21, grifo nosso).
\end{abstract}

Nota-se uma clara tentativa de ocultação da crise, seja através do sistema que procura ignorar a manifestações do conflito, como também pela sua deturpação. Quando esses conflitos aparecem de modo inegável, de modo que se impossibilite sua ocultação e ou mistificação, passam a ser tratados como meros efeitos ou defeitos a serem corrigidos, geralmente, pela intervenção do Estado.

A crise estrutural do sistema do capital como um todo está destinada a piorar consideravelmente, atingindo não somente o mundo das finanças globais, mas alcançando todos os domínios da vida social, econômica e cultural, explicitando Mészáros (2011a, p. 17) que alega que não se trata de uma crise financeira maciça, mas da possibilidade de autodestruição tanto do sistema reprodutivo social como da própria humanidade e, para exemplificar, indaga o que aconteceria com o nosso planeta caso o restante do mundo adotasse o mesmo padrão de consumo dos Estados Unidos.

Outro aspecto sobre a crise estrutural do capital é que ela não é decorrente da escassez, mas é o resultado da superprodução, ou seja, a oferta de excesso de produtos sem o 
correspondente aumento da procura, fato que gera a queda dos preços das mercadorias causando a diminuição do lucro.

Como parte das estratégias para solucionar o problema da superprodução, o capital em seu sistema de produção de mercadoria decresce o valor de uso das coisas, que se caracteriza pela redução de vida útil das mercadorias, o que em grande medida corrobora com a devastação do meio ambiente: “[...] com desperdício voraz os limitados recursos do nosso planeta, o que é posteriormente agravado pela poluição e pelo envenenamento do meio ambiente humano, decorrentes da produção em massa de lixo e afluentes” (MÉSZÁROS, 2011a, p. 73).

Os seres humanos são, por sua vez, convertidos em "força de trabalho necessária", que, sob o jugo do capital, tornam-se uma "mercadoria comercializável", assim como todas as outras.

Como consequência do aprofundamento da crise estrutural, temos a subjugação do valor de uso ao valor de troca e a realização de uma produção mais intensamente voltada para a autorreprodução do capital, e apenas em segundo plano para o atendimento das necessidades humanas, intensificando com isto as consequências destrutivas como a precarização do trabalho e a destruição da natureza.

O desemprego, por sua vez, atinge um caráter crônico de desemprego estrutural, que já não se limita ao exército de reserva. Destacando-se também a erosão do trabalho contratado e regulamentado, que vem sendo substituído pelas diversas formas de "cooperativismo", "empreendedorismo", "trabalho voluntário", "trabalho atípico", que por seu turno, caminham em direção a uma precarização estrutural da força de trabalho.

Neste momento de crise estrutural, marcado pela destruição das forças produtivas do meio ambiente, assim como da força humana de trabalho, a partir de um trabalho precarizado e à margem do processo produtivo, o capital busca estratégias para garantir o seu ciclo reprodutivo, implantando um enorme processo de reestruturação. Complexos como o da educação, por exemplo, passam a ser tomados como instrumentos capazes de maximizar o processo produtivo, tanto no que se refere à formação do trabalhador útil ao novo processo de produção capitalista, quanto no processo de manipulação das consciências. Neste processo, o Estado passa a assumir papel central no que concerne à sua operacionalização, estritamente imbricada à neoliberalização e ao peso mandatário dos organismos internacionais, como o FMI e o Banco Mundial, com destaque para o compromisso assumido a partir da Conferência Mundial de Educação para Todos e suas metas.

A Conferência Mundial de Educação para Todos, realizada em 1990, é uma boa ilustração da relação entre as reformas, demandadas pelo capital em crise estrutural e o 
complexo educativo. O evento realizou-se em Jomtien, na Tailândia, e teve o patrocínio do Banco Mundial. A partir dessa conferência, os 155 países participantes e as 120 organizações não governamentais assinaram e aprovaram a Declaração Mundial Sobre Educação para Todos: Plano de Ação para Satisfazer as Necessidades Básicas de Aprendizagem, cujo compromisso principal referia-se à universalização da educação básica.

Com base na Conferência de Jomtien, foram traçadas seis metas para a educação: meta 1 - expansão dos cuidados e atividades para crianças em idade pré-escolar; meta 2 - acesso universal ao ensino fundamental; meta 3 - melhoria da aprendizagem; meta 4 - redução do analfabetismo adulto; meta 5 - expansão de oportunidade de aprendizagem para adultos e jovens; meta 6 - a construção de conhecimentos, habilidades e valores para uma vida melhor e um desenvolvimento sustentável. O Banco Mundial, com objetivo de garantir o cumprimento das metas aferidas no respectivo documento, determina que todos os acordos socioeconômicos a partir de então terão como pré-requisito o atendimento das reformas "exigidas".

A Declaração Mundial sobre Educação para Todos passa a ser um dos principais documentos norteadores das políticas da educação brasileira dos anos 1990. O referido documento se inicia com um relato dos problemas educacionais, trazendo dados como o número de crianças que não têm acesso ao ensino primário, de adultos analfabetos, ou seja, os dados de falta de escolaridade. Na sequência, apresenta o que ele define como "quadro sombrio de problemas" relacionados ao quadro socioeconômico, para tentar relacioná-los:

Esses problemas atropelam os esforços enviados no sentido de satisfazer as necessidades básicas de aprendizagem, enquanto a falta de educação básica para significativas parcelas da população impede que a sociedade enfrente esses problemas com vigor e determinação (UNESCO, 1990, p. 1).

Ressalta-se que para a referida declaração, o mundo está às vésperas de um novo século carregado de esperanças e possibilidades, categorias essas que poderiam se relacionar àquela que Mészáros (2011a) descreveu como confiança, que, segundo o referido autor, tem sido a palavra repetida para encobrir todos os demais diagnósticos sobre a crise com o objetivo de mistificação geral.

Outro aspecto que destacamos no Plano de Ação apresentado são as constantes recomendações de cooptar para a educação, novos agentes de financiamento e auxiliares no processo de atendimento as necessidades básicas de aprendizagem. Temos como exemplo o artigo $7^{\circ}$ que dispõe como um dos objetivos o fortalecimento de alianças, justificando este que:

As autoridades responsáveis pela educação aos níveis nacional, estadual e municipal têm a obrigação prioritária de proporcionar educação básica para 
todos. Não se pode, todavia, esperar que elas supram a totalidade dos requisitos humanos, financeiros e organizacionais necessários a esta tarefa. Novas e crescentes articulações e alianças serão necessárias em todos os níveis [...] (UNESCO, 1990, p. 5).

Defesa também presente no artigo $9^{\circ}$, que apresenta o argumento: "Para que as necessidades básicas de aprendizagem para todos sejam satisfeitas mediante ações de alcance muito mais amplo, será essencial mobilizar atuais e novos recursos financeiros e humanos, públicos, privados ou voluntários” (UNESCO, 1990, p. 5). Em outro trecho, chega a apelar “[...] aos governos, às organizações interessadas e aos indivíduos, para que somem a este urgente empreendimento" (UNESCO, 1990, p. 6).

Em consonância com as demandas postas pelo capital, o governo brasileiro elaborou o "Plano Diretor da Reforma do Aparelho do Estado", documento que "[...] define objetivos e estabelece diretrizes para a reforma da administração pública brasileira" (BRASIL, 1995, p. 6), justificando que:

Um dos aspectos centrais desse esforço é o fortalecimento do Estado para que sejam eficazes sua ação reguladora, no quadro de uma economia de mercado, bem como os serviços básicos que presta e as políticas de cunho social que precisa implementar" (BRASIL, 1995, p. 6).

De acordo com o referido Plano Diretor (1995, p. 11), o Estado seria incapaz de “[...] atender com eficiência a sobrecarga de demandas a ele dirigidas, sobretudo na área social. A reforma do Estado não é, assim, um tema abstrato: ao contrário é algo cobrado pela cidadania", e assim concebe a reconstrução do Estado, como meio pelo qual este possa resgatar sua autonomia financeira e sua capacidade de programar políticas públicas.

A reforma ora proposta tinha como orientação reduzir as funções do Estado, passando este de executor, ou prestador direto dos serviços, para regulador e provedor destes, com destaque para os programas de Educação e Saúde considerados essenciais. A governança seria reforçada através da adoção gradual de um novo modelo de administração, “[...] de um tipo de administração pública burocrática, rígida e ineficiente, voltada para si própria e para o controle interno, para uma administração pública gerencial, flexível e eficiente, voltada para o atendimento do cidadão (BRASIL, 1995, p. 13).

A Constituição Federal de 1988 também apresenta uma correlação com as propostas da respectiva reforma do Estado quando prevê, por exemplo, em seu Art. $205^{\circ}$ que "A educação direito de todos e dever do Estado, será promovida e incentivada com a colaboração da sociedade, visando ao pleno desenvolvimento da pessoa, seu preparo para o exercício da cidadania e sua qualificação para o trabalho" (BRASIL/CF, 1998, p. 121). 
A Reforma do Aparelho do Estado (1995) desregulamentou a economia e abriu o mercado através de medidas de privatização e descentralização de políticas públicas, para os níveis estaduais e municipais. Observa-se também a transferência da responsabilidade de oferta de serviços sociais, como os de educação e de saúde, para os municípios, assim como a diminuição dos investimentos federais para essas políticas.

Tal perspectiva vem em atendimento às demandas do Banco Mundial que, a partir dos anos 1980, juntamente com outros organismos multilaterais de financiamento, passam a "[...] desempenhar o papel de agentes no gerenciamento das relações de crédito internacional e na definição de políticas de reestruturação econômica, por meio de programas de ajuste estrutural" (MENDES SEGUNDO, 2005, p. 47), procurando inclusive associar a lógica da governabilidade à reforma estrutural sob a premissa de que a não realização da reforma ensejará em forte crise política, pois segundo a autora, (2005, p. 59):

O Banco Mundial, na condição de responsável pelos recursos oferecidos aos países periféricos, vai procurar manter a ordem estabelecida mediante redução dos gastos públicos, desregulamentação dos mercados, abertura econômica, privatização das empresas estatais e diminuição do papel social que o Estado poderia vir a ter.

Com o argumento de que o Estado é grande demais e lento para agir, o pressuposto da Reforma do Aparelho do Estado pretendia ampliar a eficiência e a eficácia principalmente sobre a utilização de recursos públicos, pressuposto este também presente no Plano de Ação para Satisfazer as Necessidades Básicas de Aprendizagem, (1990, p. 11), sobre o que, no item 23, prevê:

Promover uma educação básica eficaz não significa oferecer a mais baixos custos, porém utilizar, com maior eficiência, todos os recursos (humanos, organizativos e financeiros), para obter os níveis pretendidos de acesso e desempenho escolar. As considerações anteriores relativas à relevância, à qualidade e à equidade não se constituem alternativas à eficácia, representam, antes, as condições específicas em que esta deve ser obtida. De fato, em alguns programas, a eficácia irá exigir um aumento, e não uma redução de recursos. No entanto, se os recursos existentes podem ser utilizados por um número maior de educandos ou se os mesmos objetivos de aprendizagem podem ser alcançados a um menor custo por aluno, então será facilitada à educação básica a consecução das metas de acesso e desempenho para os grupos atualmente não assistidos.

O plano de ação elaborado a partir da Conferência de Jomtien, assim como a Reforma do Aparelho do Estado, apresenta uma forte tendência a requisitar as instituições privadas e não estatais a compartilhar a oferta de serviços públicos, tais como a educação. 
A gestão democrática surge então como um princípio sob o qual deverá ser organizada a Educação, que fora regulamentado através da Constituição Federal de 1988 e a Lei de Diretrizes e Bases - LDB 9394/96, e também se encontra articulado com as orientações dos organismos internacionais e consequentemente com a Reforma do Aparelho do Estado, conforme demonstraremos a seguir.

A LDB em seu art. 15 aponta como condição para o estabelecimento da gestão democrática que os sistemas de ensino assegurem “[...] às unidades públicas de educação básica que os integram, progressivos graus de autonomia pedagógica e administrativa e de gestão financeira, observadas as normas gerais de direito financeiro" (BRASIL/MEC, 1998, p. 168), autonomia esta que favorece as orientações formuladas a partir da Conferência de Jomtien, como por exemplo, o fortalecimento das alianças e articulações, a mobilização de recursos financeiros e humanos, públicos ou privados para educação, considerados essenciais. A Reforma do Aparelho do Estado (1995) também se encontra articulada com o artigo 15 da LDB, quando este defende uma administração pública gerencial e pressupõe como um das estratégias garantir a autonomia da administração na gestão dos recursos financeiros, materiais e humanos para que este possa atingir os objetivos propostos.

Segundo Mészáros (2009), neste período de crise estrutural do capital, é constante a defesa acerca da ideologia da "modernização" e, nesse tom, apregoa-se que os países que não melhoraram os seus níveis de empregabilidade não o fizeram por não serem capazes de se modernizar, passando a propaganda então a defender "democracia e desenvolvimento" como novos objetivos a serem alcançados. Percebemos que "democracia e desenvolvimento" também se relacionam com o princípio da gestão democrática, vejamos como exemplo o que dispõe o Ministério da Educação - MEC (2007, p. 28):

Outra política que certamente concorrerá para a democratização da educação básica é a gestão democrática nas escolas públicas, já estabelecida pela Constituição Federal de 1988, mas ainda carente de regulamentação. Com isso, espera-se que a experiência democrática a ser vivenciada pelos diversos segmentos sociais seja o caminho tão esperado para a conscientização da sociedade a respeito da importância da educação para o desenvolvimento econômico, cultural e político do Brasil. Sabe-se que a educação sozinha não resolverá os problemas estruturais do Brasil, mas sabe-se também, que sem ela, eles certamente não poderão ser resolvidos.

Diante da crise econômica a educação enquanto importante complexo de mediação para a reprodução social, também é atingida, das mais variadas formas. Segundo Tonet (2003), uma dessas maneiras é apontar como inadequadas as formas anteriores de educação frente ao novo modelo de produção, bem como das novas relações sociais. No caso específico da gestão 
educacional, critica-se o modelo anterior que toma os princípios administrativos das empresas para escola, e toma-se a gestão democrática como novo modelo de prática, vejamos o cenário em que ocorre a referida mudança paradigmática.

\section{Gestão Democrática e Educação: interfaces e relações}

O início da década de 1980, no Brasil, caracterizou-se pela perspectiva de ressurgimento de um Estado democrático. Segundo Rodrigues (2001, p. 12), nos anos 1980 existiam muitas opiniões relativas à forma como deveria ocorrer a renovação das instituições e o estabelecimento do regime participativo, no entanto, conforme ressalta a autora, a pressão dos movimentos sociais foi fundamental "[...] para a conquista da abertura, mas não para garantir sua condução realmente democrática".

Em meados de 1983, o movimento em defesa das eleições diretas, chamado "Diretas já”, intensifica-se ganhando vários adeptos, constituindo-se em diferentes movimentos de luta, o que culminou com a aprovação, no ano de 1988, de uma nova Constituição para o país que, dentre outras medidas, previa a suspensão da censura, o reconhecimento do direito de greve e a não intervenção do Estado nas organizações sindicais.

Foi nesta conjuntura político econômico que surgiram os primeiros estudos na área educacional que criticavam o modelo Taylorista-Fordista de administração para a organização do sistema educacional, em favor de um modelo que previa, sobretudo, maior participação e controle da sociedade.

Conforme historiciza Tonet (2005), por volta da década de 1980, muitos educadores comprometidos com a classe trabalhadora, e que se esforçavam em pensar em uma educação que pudesse contribuir para uma transformação revolucionária da sociedade, partindo “[...] de uma espécie de choque, no âmbito da educação, que instituiria fundamentos inteiramente novos" (TONET, 2005, p. 8), substituíram essa perspectiva da revolução, pela articulação entre educação e cidadania. Levando a formação da chamada esquerda democrática, que se dividia entre os que defendiam a via democrática para o socialismo e os que fariam uma crítica ao marxismo.

Na educação, a articulação educação/revolução, passou em grande medida, a ser substituída pela articulação entre educação e cidadania/democracia. Segundo Tonet (2005, p. 8) “De lá para cá, falar em educação cidadã, em educação para cidadania, escola cidadã, tornouse mais ou menos lugar comum, dando por suposto que cidadania seria sinônimo de liberdade”. 
Autores como Paulo Freire e Gaudêncio Frigotto foram exemplos de educadores que, segundo Tonet (2005), abandonaram a luta pela construção de uma sociedade efetivamente livre, constituída por pessoas plenamente autônomas, sujeitos da história, pela luta em torno da formação de cidadãos, o que significaria que "[...] para as classes populares, lutar pela cidadania não seria lutar por uma forma determinada de liberdade, nem sequer por uma mediação para a efetiva liberdade, mas pela liberdade tout court" (TONET, 2005, p. 8).

Paulo Freire, por exemplo, escreveu uma obra intitulada Alfabetização como elemento de formação da Cidadania, em que defende a tese de que a alfabetização pode ser um instrumento para formação do cidadão, e, portanto, um ato político, e jamais neutro. Contudo, ressalta Tonet $(2005$, p. 8$)$ que:

\begin{abstract}
Nada haveria a objetar a estas afirmações, se não fosse pelo fato de que o grande objetivo que norteou toda a reflexão e todo o trabalho prático de Paulo Freire foi a luta pela construção de uma sociedade efetivamente livre [...]. De modo que, na medida em que ele mesmo não faz nenhuma restrição, parece razoável admitir que por plenitude da cidadania ele quer significar plenitude de liberdade, entendida, obviamente, como um processo de construção permanente.
\end{abstract}

Frigotto também manifesta, segundo Tonet (2005), a influência da chamada via democrática para o socialismo, vejamos um trecho da obra A educação e a crise do capitalismo real:

Os novos movimentos sociais, partidos políticos e sindicalismo de novo tipo e as políticas educacionais que se desenvolvem em várias capitais e inúmeros municípios por estas forças políticas [...] sinalizam que a alternativa [da educação numa perspectiva socialista democrática] está em curso no plano político-ideológico, ético e teórico-prático (FRIGOTTO apud TONET, 2005, p. 12).

O texto Administração da educação, poder e participação, escrito por Miguel Arroyo, fora, segundo Souza (2006, p. 19), um artigo “[...] citado por diversos outros autores como sendo o trabalho provocador, no campo da gestão escolar, por novos olhares mais críticos para com os objetos que lhe são próprios". Na referida redação, Arroyo (1979, p. 36), elabora uma “[...] reflexão sobre as dimensões políticas das tendências atuais na administração no Brasil”, em que estabelece um diálogo que questiona a responsabilização do sistema educacional pelos problemas crônicos que o afetam, justificando o autor que a origem dos problemas não está na escola, ou na administração, mas em um modelo de sociedade.

Arroyo (1979), por sua vez, defende a democratização da educação, no sentido de as decisões do Estado serem debatidas e controladas pela opinião pública, com a criação de 
mecanismos que possibilitassem maior participação da sociedade na política, administração e planejamento do sistema educacional.

Moacir Gadotti (1999, p. 9), ao escrever sua experiência de gestão compartilhada no livro intitulado Escola Cidadã, defende a seguinte tese: “A escola que está perdendo a sua autonomia também está perdendo a sua capacidade de educar para Liberdade”. O autor alega que Sócrates já defendia a autonomia como princípio educativo. Em sua obra, Gadotti descreve sua experiência de gestão compartilhada. Para ele, após essa vivência, a tese de uma transformação radical e revolucionária da sociedade deveria ser abandonada, pois o mais importante é a defesa de pequenas mudanças. Nas palavras do autor:

$\mathrm{Na}$ época eu pensava que as pequenas mudanças impediam a realização de uma grande mudança... Hoje, a minha certeza é outra... hoje eu creio que é na luta cotidiana, no dia-a-dia, mudando passo a passo, que a quantidade de pequenas mudanças numa certa direção oferece a possibilidade de operar a grade mudança (GADOTTI, 1999, p. 26).

$\mathrm{Na}$ educação, a defesa do princípio da gestão democrática entendida como o estabelecimento de relações de igualdade em função da socialização do poder de decisão, supondo na direção da escola, órgãos máximos colegiados, compostos de vários segmentos organizados da comunidade escolar (professores, alunos e funcionários, pais e representantes da sociedade, ligados à escola pública) se articulam aos princípios da via democrática para o socialismo, na medida em que defende a democracia como um espaço de formação do cidadão, e de espaços democráticos.

A gestão democrática é um princípio garantido pela Constituição Federal (CF) de 1988, que prevê como um dos princípios sob os quais será ministrado o ensino, assim como a Lei de Diretrizes e Bases da Educação Nacional (LDB) nº 9.394 de 1996. Contudo, ressaltamos que não existe previsão legal que assegure a forma como será definida a gestão democrática do ensino público na educação básica, devendo esta, segundo a LDB em seu Art. 14, ser organizada de acordo com as suas peculiaridades e conforme os seguintes princípios: a) participação dos profissionais da educação na elaboração do projeto pedagógico da escola; b) participação das comunidades, escolar e local, em conselhos escolares ou equivalentes.

A gestão democrática é um princípio constitucional que prevê, dentre outros, um modelo de administração que se contrapõe ao modelo burocrático, vejamos o que nos propõe o governo através do documento publicado pelo Ministério da Educação (MEC, 2006, p. 8): “Os sistemas municipais de ensino carecem de instrumentos eficazes de gestão que lhes permitam identificar 
com exatidão os problemas, formular, implementar e monitorar as políticas desenvolvidas no âmbito municipal".

Em outro momento, a redação oficial descreve como seria essa forma de organização escolar, realizada através da:

[...] adoção de novos modelos de organização administrativa e de gestão, nos quais sejam garantidos a participação popular e o controle social, baseado na concepção de gestão democrática, intersetorial, que se contrapõe aos processos de gestão gerencial, burocrático e centralizador (CONAE apud GADOTTI, 2014, p. 9)

Descentralização e participação também aparecem como pressupostos a esse modelo de gestão democrática. No entanto, ressaltamos que as três esferas governamentais: União, Estado e Municípios não têm compartilhado responsabilidades e que tradicionalmente, a descentralização tem se revelado uma prática que, em geral, se limita a transferir responsabilidades do governo central para os governos estaduais e municipais, enquanto o poder de decisão se mantém centralizado.

Deste modo, podemos afirmar que a descentralização não tem ocorrido e o que de fato localizamos são políticas de descontração de poder, caracterizado por ações que delegam “[...] determinadas funções à comunidade local, mantendo centralizadas as decisões sobre os aspectos financeiros, administrativos e pedagógicos" (VIRIATO, 2004, p. 47).

A participação, por sua vez, está contemplada na LDB no 9394/96 em seu artigo 14, quando delega a cada sistema de ensino público da educação básica, que estabeleça as normas da gestão democrática de acordo com as suas peculiaridades e seguindo os princípios: da participação dos profissionais da educação na elaboração do projeto pedagógico da escola e a participação das comunidades escolar e local em conselhos escolares ou equivalentes. Entretanto, autores como Lima (2004, p. 19) alegam que na década de 1980:

[...] as políticas implementadas na escola como formas participativas (os conselhos escolares, os grêmios, a descentralização) perderam seu caráter de controle popular pela burocratização do aparelho do Estado. Ou seja, não foram rompidas as formas de controle via centralização, mas o discurso que sustentava tais políticas persistiu em modelos participativos.

Saviani (2009) é outro autor que escreve uma obra para debater o tema democracia na escola: Escola e Democracia. Na referida obra, o autor defende a tese de que "[...] quando mais se falou em democracia no interior da escola, menos democrática foi a escola; e de como, quando menos se falou em democracia, mais a escola esteve articulada com a construção de uma ordem democrática". Isto porque o tempo em que mais se falou em democracia foi no 
período da escola nova, concebida como o método tradicional de educação antidemocrático por não considerar as diferenças individuais.

Compreende-se, então, que essa maneira de entender a educação, por referência à pedagogia tradicional, tenha deslocado o eixo da questão pedagógica do intelecto para o sentimento; do aspecto lógico para o psicológico; dos conteúdos cognitivos para os métodos ou processos pedagógicos; do professor para o aluno; do diretivismo para o nãodiretivismo; da quantidade para qualidade; de uma pedagogia de inspiração filosófica centrada na ciência da lógica para uma pedagogia de inspiração experimental baseada principalmente nas construções da biologia e da psicologia. Em suma, trata-se de uma teoria pedagógica que considera que o importante não é aprender, mas aprender a aprender (SAVIANI, 2009, p. 8).

Diante desta análise, Saviani defende que a escola no período da educação tradicional esteve mais articulada com a construção de uma ordem democrática na medida em que, neste modelo, seria papel do professor garantir a seus alunos “[...] a aquisição dos conteúdos mais ricos e sem os quais não se terá vez, não se terá chance de participar da sociedade" $(2009$, p. 45), ou seja, Saviani defende a tese de que o modelo de educação mais democrático é aquele que permite ao educando a apropriação dos conhecimentos necessários para que ele possa participar mais ativamente da sociedade.

Ressaltamos, contudo, que a educação enquanto um complexo fundado a partir do trabalho não poderia deixar de ser atravessada pelos antagonismos sociais. Segundo Tonet (2005, p. 142), "Em uma sociedade de classes, o interesse das classes dominantes será sempre o polo determinante da estruturação da educação. O que significa que ela será configurada de modo a impedir qualquer ruptura com aquela ordem social”. A luta, entretanto, pode e deve ocorrer, já que os atos humanos possuem certo grau de liberdade e que por isto não são previamente determinados, apesar disso, “[...] não se pode nutrir a ilusão de estruturar uma educação emancipadora como um conjunto sistematizado e largamente praticável em oposição a uma educação conservadora" (TONET, 2005, p. 143).

Para Tonet (2005, p. 155), “[...] uma atividade educativa que pretenda contribuir para formar homens realmente livres e sujeitos de sua história deve ter como objetivo último, a emancipação humana e não a cidadania”. A cidadania representa aquilo que Marx denominou como emancipação política, que separa a vida dos homens e mulheres em duas: uma como membro da comunidade política e outra como pessoa particular, enquanto a emancipação humana representa um espaço indefinidamente aperfeiçoável, em que serão os homens e as mulheres, e não o capital, a controlar o processo de produção. 
Quando colocamos os problemas da escola na gestão, e a gestão democrática como solução, estamos negando o princípio da totalidade, cuja matriz é a economia. Concordamos com Tonet (2005) quando este afirma que a contribuição mais importante que a educação pode oferecer para a transformação desta sociedade é exercendo seu papel específico da melhor maneira possível. Isto consiste em propiciar a apropriação dos conhecimentos acumulados pela humanidade, permitindo que o indivíduo se constitua como um ser pertencente ao gênero humano, não esquecendo a articulação destes conhecimentos com a prática revolucionária.

\section{Considerações finais}

Estamos vivendo, desde a década de 1970, uma crise histórica sem precedentes, denominada por Mészáros (2011a) de crise estrutural do capital. Uma crise que nasce em virtude do processo da superprodução, e que, pela primeira vez, assola o conjunto da humanidade, espraiando-se por todos os complexos sociais.

A educação, neste momento de crise estrutural, passa a ser tomada como instrumento capaz de maximizar o processo produtivo. Os organismos internacionais, com destaque para o Banco Mundial, passam a acompanhar e determinar mais diretamente as políticas educacionais dos países periféricos e os acordos ocorridos por ocasião da Conferência Mundial de Educação para Todos e suas metas.

O Brasil, por sua vez, adere às demandas postas pelo capital em crise e elabora a Reforma do Aparelho do Estado. Essa reforma foi um documento assinado pelo Governo Federal, e que estabelecia diretrizes para a reforma da administração pública do país.

Na Educação, temos a promulgação da Constituição Federal de 1988 e a Lei de Diretrizes e Bases $n^{\circ}$ 9394/96 como documentos que passaram a nortear as políticas educacionais, devidamente articuladas com as prerrogativas internacionais.

Apresentamos também, como marcas deste período, a centralidade da democracia, no que se refere ao momento político econômico do país. Na educação, temos o abandono acerca da articulação educação/revolução por parte de alguns educadores, que passam a defender a articulação educação, cidadania e democracia.

Concebemos, contudo, com base no marxismo clássico, que a democracia apesar de representar um avanço, não deve ser concebida como objetivo último a ser perseguido pela sociedade, pois esta não representa a liberdade efetiva, mas apenas um caminho. Uma luta que reivindique a mudança radical deve ser o horizonte a ser perseguido. Ou seja, o rompimento com o modo de produção capitalista. 
Hoje, com a crise estrutural do capital, a educação está sendo posta, mais fortemente, na agenda econômica, não somente como meio para obtenção de lucro, mas como meio de manipulação das consciências. E a gestão democrática? Surge aparentemente como forma de atender as demandas postas pela sociedade de maior participação. Em essência, todavia, o que de fato ocorre, fora a delegação à sociedade de partes das responsabilidades do governo, é o repasse à sociedade de algumas atividades de execução e acompanhamento, dando a aparência de gestão democrática.

A participação na gestão da educação, com real poder de decisão, apesar de representar um avanço, deve constituir um passo rumo a uma luta maior: a luta por uma sociedade emancipada.

\section{REFERÊNCIAS}

ARROYO, Miguel Gonzáles. Administração da educação, poder e participação. Educação \& Sociedade, São Paulo, Ano I, n. 2, p. 36-46, jan. 1979.

BRASIL. Plano diretor da reforma do aparelho do Estado: câmara da reforma do Estado. Brasília, DF: Planalto, 1995. Disponível em: https://www.planalto.gov.br/publi_04/colecao/plandi. Acesso em: 15 jan. 2014.

BRASIL. Lei n. 9.394, de 20 de dezembro de 1996. Lei de diretrizes e bases da educação nacional. Diário Oficial da União, Brasília, 23 dez. 1996.

BRASIL. Constituição da República Federativa do Brasil: promulgada em 5 de outubro de 1988, com as alterações adotadas pelas Emendas Constitucionais n. s a 42/2003 e pelas Emendas Constitucionais de Revisão n. s 1 a 6/94. Brasília: Senado Federal, Subsecretaria de Edições Técnicas, 2004.

BRASIL. Ministério da Educação. Seminário Internacional Gestão Democrática da Educação e Pedagogias Participativas. Brasília, DF. Anais [...]. Brasília, DF, 24 a 28 de abril de 2006. Disponível em: http://fne.mec.gov.br/images/doc/DocumentoFina240415.pdf. Acesso em 10 jan. 2020.

GADOTTI, Moacir. Escola cidadã. São Paulo: Cortez, 1999.

GADOTTI, Moacir. Gestão Democrática com participação popular: no planejamento e na organização da educação nacional. Brasília, 2014. Disponível em: http://conae2014.mec.gov.br/images/pdf/artigogadotti_final.pdf. Acesso em: 11 jan. 2014.

LIMA, Antônio Bosco. Políticas educacionais e o processo de "democratização" da gestão educacional. In: BOSCO, A. et al., (Orgs.). Estado, políticas educacionais e gestão compartilhada. São Paulo: Xamã, 2004. 
MENDES SEGUNDO, Maria das Dores. O Banco Mundial e suas implicações na Política de Financiamento da Educação Básica do Brasil: o Fundef no centro do debate. Orientadora: Maria Susana Vasconcelos Jimenez. 2005. 243 f. Tese (Doutorado em Educação) - Universidade Federal do Ceará, Fortaleza, UFC, 2005.

MÉSZÁROS, István. O século XXI: socialismo ou barbárie. Trad. Paulo Cezar Castanheira. São Paulo: Boitempo, 2009.

MÉSZÁROS, István. A crise estrutural do capital. Trad. Francisco Raul Cornejo et al. São Paulo: Boitempo, 2011a.

MÉSZÁroS, István. Para Além do Capital: rumo a uma teoria da transição. Trad. Paulo Cezar Castanheira, Sérgio Lessa. São Paulo: Bointempo, 2011b.

RODRIGUES, Marly. A DÉCADA DE 80 - Brasil: quando a multidão voltou às praças. São Paulo: Ática, 2001.

SAVIANI, Dermeval. Escola e Democracia. Campinas, SP: Autores Associados, 2009.

SOUZA, Ângelo Ricardo. Perfil da gestão escolar no Brasil. Orientador: José Geraldo Silveira Bueno. 2019. 336 f. Tese (Doutorado em Educação) - Pontifícia Universidade Católica de São Paulo. São Paulo, 2006. Disponível em:

http://livros01.livrosgratis.com.br/cp026427.pdf. Acesso em: 01 set. 2019.

TONET, Ivo. A educação numa encruzilhada. In: MENEZES, Ana Maria Dorta de Menezes; FIGUEIREDO, Fábio Fonseca Figueiredo (Orgs). Trabalho, sociabilidade e educação: uma crítica à ordem do capital. Fortaleza: UFC, p. 201-219, 2003. Disponível em:

www.ivotonet.xpg.com.br. Acesso em: 15 fev. 2012.

TONET. Ivo. Educação, cidadania e emancipação humana. Ijuí, Unijuí, 2005. Disponível em: www.ivotonet.xpg.com.br. Acesso em 24 set. 2019.

UNESCO. ORGANIZAÇÕES DAS NAÇÕES UNIDAS PARA A EDUCAÇÃO, CIÊNCIA E CULTURA. Declaração Mundial sobre Educação para Todos (Conferência de Jomtien). Plano de ação para satisfazer as necessidades básicas de aprendizagem. Tailândia: UNESCO, 1990. Disponível em: https://www.unicef.org/brazil/declaracao-mundial-sobre-educacaopara-todos conferencia-de-jomtien-1990. Acesso em: 01 nov. 2019.

VIRIATO, Edaguimar Orquizas. Descentralização e desconcentração como estratégia para redefinição do espaço público. In: BOSCO, A. et al., (Orgs.). Estado, políticas educacionais e gestão compartilhada. São Paulo: Xamã, 2004. 


\section{Como referenciar este artigo}

SIDOU, Adriana Mota de Oliveira; GUERRA, Agercicleiton Coelho; SANTOS, José Deribaldo Gomes. Gestão democrática e crise estrutural do capital: alguns apontamentos. Revista on line de Política e Gestão Educacional, Araraquara, v. 24, n. 2, p. 314-331, maio/ago., 2020. e-ISSN: 1519-9029. DOI: https://doi.org/10.22633/rpge.v24i2.13283

Submetido em: 10/02/2020

Aprovado em: 20/03/2020

Publicado em: 09/04/2020 